\title{
"I want complete freedom": car use and everyday mobility among the newly retired
}

\author{
Jessica Berg ${ }^{1,2} \cdot$ Lena Levin ${ }^{1}$ • Marianne Abramsson ${ }^{2}$ • Jan-Erik Hagberg ${ }^{2}$
}

Received: 16 January 2015 / Accepted: 2 September 2015 /Published online: 12 September 2015

(C) The Author(s) 2015. This article is published with open access at SpringerLink.com

\begin{abstract}
Purpose To investigate car use among newly retired people, to explore to what extent car transport is used for everyday mobility and how it is valued in comparison to other transport modes.

Methods The data consists of travel diaries and qualitative interviews with 24 individuals, aged between 61 and 67, living in a middle-sized Swedish city. They were recruited via the local branch of one of the main associations of pensioners, one large employer in the municipality, and through another study. The informants filled in a travel diary during 1 week that were analysed by VISUAL- TimePAcTS, an application for visualising and exploring activity diary data. The semistructured qualitative interviews were analysed using a qualitative content analysis.

Results The car was used for several trips daily and often for short trips. The informants had a lot of everyday projects that they would not be able to perform if they did not have access to a car. The importance of the car does not seem to have changed upon retirement, albeit it is partly used for other
\end{abstract}

Jessica Berg

jessica.berg@vti.se

Lena Levin

lena.levin@vti.se

Marianne Abramsson

marianne.abramsson@liu.se

Jan-Erik Hagberg

jan-erik.hagberg@liu.se

1 Swedish National Road and Transport Research Institute (VTI), SE- 58195 Linköping, Sweden

2 National Institute for the Study of Ageing and Later Life (NISAL) Department of Social and Welfare Studies, Linköping University, SE- 60174 Norrköping, Sweden reasons than before. The informant's social context implies new space-time constraints. Commitments to family members, engagement in associations and spouses' occupations affect how much and when they use the car, and their overall mobility.

Conclusions In contrast to much research on older people's mobility that has studied slightly older people, this study have focused on a specific group that are relatively healthy, welloff, and have the possibility to choose between different modes of transport. By combining travel diaries and qualitative interviews, we have explored how newly retired people reason as regard their travel behaviour but also how they actually travel. Although the car was used more than other transport modes, being able to walk and cycle now that they had more time as retirees was highly valued. Our results indicate that urban residents that are retiring now and in the future are a key target group in transport planning when it comes to reduce car use in favour of slow modes of transport.

Keywords Car use $\cdot$ Mobility $\cdot$ Retirement $\cdot$ Older people . Space-time restrictions

\section{Introduction}

A large proportion of the cohorts born after the Second World War who are retiring have driving licences, and use the car to a great extent for everyday transport $[1,2]$. This holds good for Sweden as well as for many other Westerns countries. Frequent car use is said to continue well into old age in the retired population, which raises questions of future implications for mobility when the ability to drive deteriorates $[1,3,4]$. Travel behaviour is strongly influenced by activities that have to be carried out during the day and by individual preconditions for mobility $[5,6]$. Demands for mobility have been shown to be 
affected by life course transitions and key events [7, 8]. As the everyday structure changes for different reasons, people are more likely than otherwise to reconsider their travel behaviour. As newly retired, people are searching for a new everyday structure with new activities other than work, to fill the day [9]. Accordingly, knowledge about life stages, such as retirement, is of central importance for transport planning and decisions aiming to influence people's travel behaviour and support them with eventually new mobility solutions.

The present study is based on travel diaries grounded in a time-geographic approach and qualitative interviews with newly retired people living in a medium-sized city in Sweden. The overall aim is to investigate car use upon retirement. More specifically, we will explore to what extent car transport is used for everyday mobility in this phase of life and how it is valued in comparison to other transport modes. Much research on mobility among seniors has concerned older age-groups than the one that is in focus in our study [10-13]. Urban residents who have only recently retired nuance the picture of older people's mobility for at least three reasons: first, they are at an age when most people do not experience health decline, second, they have close access to shops and services and, third, they are in a stage of life with increased free time at their own disposal.

The article is organised as follows. We will first describe the time-geographic approach, followed by a short overview of previous research on older people's car use. That is followed by a presentation of method, data and analysis. The subsequent section presents the empirical findings based on travel diaries and qualitative interviews. The article ends with a discussion of the main findings.

\section{A time-geographic approach for studying transport intertwined in everyday contexts}

The time-geographical approach, developed by Hägerstrand [14] and further developed by Ellegård [6], is based on the assumption that everyday life consists of activities that take time to implement and perform and are always situated somewhere. The individual uses different resources such as knowledge, tools, and objects in order to perform those activities. However, central to this approach is the fact that the individual's ability to use these resources and to carry out activities is subject to various constraints. Three types of constraints limit individual actions: Capability constraints concern the individual's knowledge, physical and mental capacity and material resources; coupling constraints are the interactions between the individual and other people, objects and places; authority constraints represent laws and regulations as well as societal and cultural norms affecting individual actions and behaviours. According to Giddens [15], constraints are not merely restrictive, but can also enable action. In this study, these constraints will be explored in order to understand how different preconditions in an individual's daily life shape mobility and influence transport mode choices in a middle-sized Swedish city. Hägerstrand [16] emphasises that humans, society, nature and technology are related to each other and that we are dependent on our material surroundings in order to live our lives. The expansion of various technical systems for housing and transportation, such as car use, has become so integral a part of our everyday lives that we do not reflect on our dependence on them [17]. Thus, in order to understand human action and behaviour, people should be studied within their everyday life contexts. Within the time-geographical conceptual framework there are four contexts that will be explored in the present study: project, activity, social, and geographical contexts $[6,18]$. The project context concerns the activities performed in order to fulfil short-term or long-term goals. For example, the household administration project might include paying bills, making a budget and posting a parcel. The activities constituting a project are seldom carried out in sequential order, rather they can be spread out during a short or a long spell of time. The activity context contains all the activities carried out within different projects. Activities do not occur randomly, rather there is an underlying structure formed by our basic needs, such as eating and sleeping, as well as commitments that bind us to certain places at certain times, such as work. The social context concerns all the individuals and networks that in one way or another are involved in order for activities to be carried out. Some activities cannot be carried out without interactions between people, while other activities are impeded by other people. The geographical context concerns places where activities are performed, and how, when and for how long people have to move between places as well as how the locations of places and materials generate movement. Although each and every one of these contexts concerns one dimension in everyday life, studied together they can display complex patterns of the individual's time-space use.

\section{The influence of life course transitions on transport}

Travel behaviour has been shown to be relatively stable throughout the life course. However, key events and transitions influence travel behaviour as people adapt to new circumstances and learning processes, which has been highlighted in research on mobility biographies [7, 19]. In recent years, a vast amount of studies have investigated the implications of key events and transitions on mode choice decisions, car ownership, commuting distances and attitudes towards available mode alternatives $[8,20,21]$. These quantitative studies focused mainly on a working population and did not consider how travel behaviour is embedded in the context of everyday life. Overall, there is a dearth of research on late life transitions and their influence on mode choice according to people's own 
experiences and individual contexts. It can be expected that travel patterns may change as the individuals search for other ways to structure everyday life after leaving paid work [9]. Shopping and service errands that previously had to be carried out after working hours, might after retirement be carried out at other times or on several occasions during the day, provided the shops are open. Further, activities or new commitments after retirement might allow or demand other transport modes than those previously used between home and the workplace. This study explores car use among people that in other studies are usually defined as "old". However, the focus here is on those that are newly retired.

\section{Older people's travel behaviour and car use}

Overall, preconditions and needs for mobility differ widely between groups based on socioeconomic factors, health, gender and between urban and rural older people [22]. The number of journeys made by people aged 65 years and older is smaller than in younger age groups and continues to decrease with age [23]. However, people over 60 years of age make more trips today by car than comparable age groups did 20-25 years ago [2]. This is partly explained by the fact that many more have driving licences and are car owners, especially among older women. The Swedish national travel survey shows that women aged 65-84 use walking as their main transport mode, while men in the same age group mostly go by car [23]. Women are car passengers to a greater extent than men and use public transport more often. The baby boomersthe cohorts born after the Second World War (roughly 1945-54) will constitute a large proportion of the older population during the next few decades. People in this generation are generally healthier, they have more money, and will live longer after retirement compared to previous generations of pensioners, although there are differences within generations [24]. During the baby boomers' childhood years, the car became an increasingly important means of transport [25]. In Sweden, mass motorism seriously took off in 1950, and by 1960 Sweden was the most motorised country in Europe. Between 1960 and 1975 motorism was spread across all social classes and in all parts of Sweden. The baby boomers are thus the first generation in Sweden to have grown up with the selfevident fact of most households owning at least one car. Lately, several studies have paid special attention to travel patterns and car use among the forthcoming older generations, especially the baby boomers $[1,3,26]$. Based on their life-course experiences, which differ from their parents' and grandparents', travel patterns in this generation can be expected to be different as well. However, few studies have specifically addressed how retirement influence mode choice and experiences of mobility in the forthcoming older generations. We attempt to contribute to filling this knowledge gap.

A vast amount of studies have explored the meaning that people ascribe to the car. It has been described as convenient, as giving them a sense of freedom and independence [27], as enabling an active life [28], a symbol of status [29], important in caring for others [30], enjoyment and pleasure in driving, and as a tool to fulfil aesthetic needs for undirected travel [31]. Spontaneous pleasure trips, which have been shown to be important for quality of life, cannot easily be replaced by public transport [32]. Some researchers state that being able to drive or having a car available in the household contributes to healthy and active ageing, as it allows older people to maintain their activities and participate in society $[33,34]$. Older people without driving licences report wanting to make more trips than they are able to, which indicates that there are inequalities in older people's mobility due to car availability [35]. On the other hand, some researchers argue that car dependency among older people may lead to restricted mobility once they have to give up driving for health reasons $[4,27$, 36]. Other studies point out that car dependency among a growing older population will contribute to increased risks to vulnerable road users, decreased physical activity and increased carbon dioxide emissions [37]. Alternatives to car use that fit older people's needs must therefore be provided in order to maintain sustainable mobility among older people. This study explores to what extent car transport is used for everyday mobility among the newly retired and how it is valued in comparison to other transport modes.

\section{Methodology}

\subsection{Participants}

This study was based on travel diaries and qualitative interviews with 24 individuals (12 men and 12 women), aged between 61 and 67 and living in Norrköping, a middle-sized Swedish city with approximately 130,000 inhabitants. Norrköping as the location was a strategic choice because the city offers a wide variety of transport modes, so that the car is not the only option for mobility. There are walking and biking paths throughout the city and the public transport system includes a tram service as well as local, regional, and national buses and trains. The public transport offered discounted fares for persons aged 70 and over at the time of the interviews. The informants had been retired for about 1 year from work in Norrköping at the time of the study, but some of them were working part time. They were recruited via the local branch of one of the main associations of pensioners (the Swedish Association for Senior Citizens, SPF), one large employer in the municipality, and through another study 
within this research project. Two of the informants did not have driving licences; one of these two had access to a car in the household, the other one did not. One informant with a driving licence did not own a car but sometimes borrowed one. All the other informants had a driver's licence and access to a car. They were of similar age but differed in terms of gender, marital status, housing tenure, income levels, profession, and work experience. Their health status allowed them to use a variety of transport modes.

\subsection{Data collection methods and analysis}

During the first week of October 2011, the informants recorded details of every trip ${ }^{1}$ they undertook each day during that week in a travel diary. The weather at the beginning of the diary week was sunny but windy and about $15^{\circ}$ Celsius. At the end of the week it was rainy and a little bit colder, and $5-10^{\circ}$ Celsius. The columns in the diaries consisted of: start and end time of the trip, where the trip began and ended, purpose, mode of transport, and companion. The diary method is useful in order to capture how people actually behave and not only what they retrospectively say what they recall doing. The qualitative interviews were semi-structured and consisted of themes regarding everyday activities, how and where people travelled, interactions with other people, experiences of mobility and of different transport modes as well as their thoughts on retirement and previous and future travel. The travel diaries were used as a basis for discussion during the interviews. The interviews were recorded digitally, with the consent of all the informants, and then transcribed verbatim. The travel diaries were analysed using VISUAL- TimePAcTS, an application for visualising and exploring activity diary data [38]. This application makes it possible to visualise activities and transport modes in sequential order for each informant (see Fig. 1). We made a qualitative content analysis of the interviews [39]. Initially, the interviews were read thoroughly, in order to familiarise ourselves with the data. In a second step, narratives and statements that in some way concerned car use were coded. MAXQDA 10 was used as a tool in this coding process. When relevant, the codes were sorted into themes according to the timegeographical approach and its concepts. For instance, codes such as "restricted without a car" were thematised as geographical context or capacity constraint. Citations that supported conclusions were translated from Swedish

\footnotetext{
${ }^{1}$ The travel diary distinguished between journeys and trips. One journey could consist of several trips, and the informants were supposed to note down each trip that constituted a journey; e.g., from home to the store (first trip), from the store to picking up the grandchildren (second trip), and back home (third trip).
}

to English by the authors. To preserve confidentiality, all names in this article are fictional.

\section{Results}

Most of the informants' time was as could be expected spent at home. According to the travel diaries, the car was the most used transport mode during the diary week. It was often used for very short trips, about 5-10 min long (one way). Many trips were also used for the purpose of making only one errand and then returning home again. Figure 1 was created in VISUAL- TimePAcTS [38], and shows what transport modes each informant used during one weekday (Monday).

The results from the travel diaries are further presented in relation to what the informants say about their car use.

We identified four main reasons why the car was particularly significant among the informants: 1) having much or heavy things to carry, 2) combining errands in different places, 3) accompanying others and offering support to others, and 4) for recreation and vacation. Two informants were renovating their house at the time of the interview and they used the car every day during the diary week in order to combine household errands and shopping for the renovation project. At the time of his retirement, Christer had a water leakage in the basement and his plans for retirement such as reading one book a week and organising digital photos had to be put on hold. During the diary week he used the car every day for the renovation project: shopping building materials, searching for materials and furniture and so on. Other means of transport than the car were therefore not an option:

\section{If you buy a plank, where do you put it? Grocery bags? \\ The car is fine! (Christer)}

Carrying and bringing home things for the renovation project thus imply coupling constraints to overcome which makes a car needed. Three informants who played golf regularly described similar situations. The car was the only option for getting oneself and one's clubs to the golf course. Many informants shopped at the out-of-town supermarkets once a week, just as they had done when they were still working. According to the travel diaries, these areas were only visited by car. Although the out-of-town supermarkets can be accessed by public transport, walking and cycling, the interviews revealed that bringing home heavy loads of groceries and other goods was difficult without the car. Lena explained that sometimes physical constraints prevented her from shopping in the city without the car:

Yes, so unfortunately I have a whiplash and can't carry too heavy bags /.../ because then I get aches and my fingers go numb. Therefore, for those reasons if I know 
Fig. 1 Transport modes used on Monday, by each informant. The vertical Y-axis shows the time starting at midnight $(00)$ and ending at midnight (24). The horizontal X-axis represents the 18 informants that filled in both start and end times of all trips
Men

Women

24

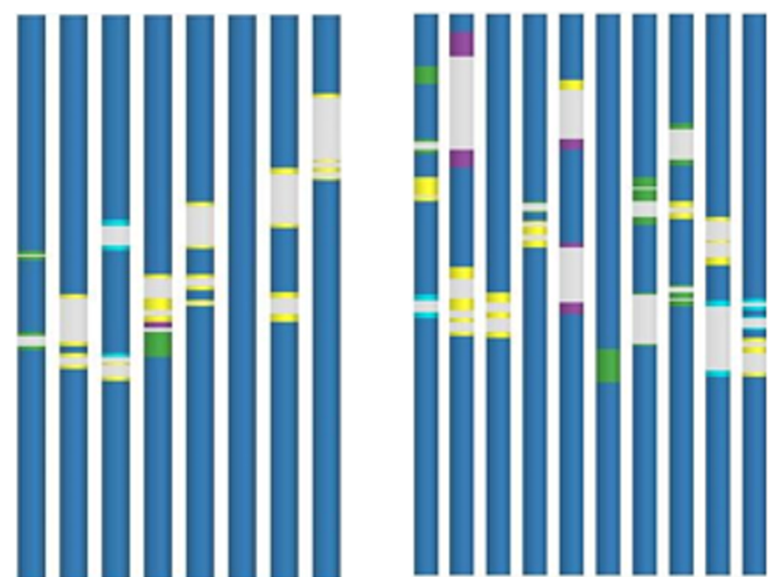

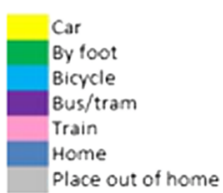

Place out of home
I'm going to buy flour and potatoes and sodas and heavy things like that, I take the car. Otherwise I would walk more and carry but I can't. (Lena)

Her travel diary revealed that she cycled, walked and drove for shopping errands depending on where she went and what kind of store she shopped at. Retirement has created new coupling constraints since many of the informants have taken on more responsibility for their grandchildren or support of their aged parents. The car was often used for helping others who needed a ride or assistance with something. Kerstin regularly picked up her grandchildren from school at different ends of the city, and so she always drove there. Gösta's daughter is a single mother and lives in another nearby city with two children. Since retirement, he had been going there regularly to take his grandchildren to their after-school activities in order to help the family. Lars explains that when his children were young he worked in another city and during his leisure time he always played hockey. He was never around for his family and he never did any household work. Since retiring he has driven his wife to her work every morning and picked her up after work in the afternoons. She cycles some days, but he said that it was now time for him to spoil her. Furthermore, his teenage grandchildren call several times a week, wanting him to pick them up from school.

They can call around one o'clock, one thirty, "Can you pick me up at a quarter past two?" If their training doesn't start until five they stay here instead of going home. I give them something to eat. (Lars)

Clearly, a person who retires seems to take on more household responsibilities when the partner is still working. When Margareta was still working, she and her husband went by car together to and from work and took turns driving. Today she drives her husband to work every day, since parking is so expensive:

Interviewer: So his everyday life has changed?

Margareta: He is so spoiled you cannot believe it, and he's the first to admit it. But on the first of January that will all be over (as he will be retiring). I do everything, take the car to the repair shop, do all the errands... It would be strange, him doing it after work when I can do it during daytime, obviously. He's in clover. (Margareta)

Accordingly, activity patterns and responsibilities have changed for both partners following Margareta's retirement, although the importance of the car has not changed. They have not considered commuting options now that she is retired. Eva talked about the expectations she had on retirement and how she would like to help her aged mother:

I would have liked to spend more time with my mother in [another city about $4 \mathrm{~h}$ drive away], she's 97 years old and lives alone /.../ Since my father got sick and couldn't drive any more there are so many things to do when I get there. And just to get out and have a look around and have coffee somewhere. Mum misses that so much. Then of course it's practical, things to buy. She has also been coming here by bus but it's a little too far and takes too many hours for her. She probably prefers the bus because she wants to manage by herself and not be waited on by us. She also needs a walker. Now I drive there to pick her up and drive her back home. She doesn't want to go by train. But if she had a car there then I wouldn't have to drive, then I would take the train. (Eva)

What Eva said exemplifies how convenient the car is both for all musts in everyday life, and for the social importance of 
getting out and about. The narratives above from Gösta, Lars and Eva also exemplify how new coupling constraints in retirement generate dependence on the car. Without a car they would be unable to help their families the way they do today.

Several arguments as to why they chose to use the car were apparent in the interviews. Just as has been shown in previous research, the car implied freedom to take spontaneous trips and to get out of town. With the car they could go at any time and to any place without having to plan beforehand.

I want complete freedom. If I want to go tomorrow, I'll go tomorrow or I'll go today. (Kent)

The thought of having to give up driving would for some of the informants imply "a disaster", "catastrophe" and be "terrible". Lena said that she would probably use taxis more, not the bus or the tram, which shows the importance of being in charge of one's own time. Most informants had not reflected on how life could be without a car. Some informants said that they were comfy and lazy and used the car even in cases where public transport was faster and cheaper. The fact that they own a car and can afford one is a reason for using it. As Lena put it:

Well, because I have kind of a new car, I cannot just let it stand there. Either I should sell it or use it I think / . . / I have a parking lot outside here and, yes... I think I have to use it. (Lena)

The car was also used for recreational activities such as getting to the forests and the archipelago about $50 \mathrm{~km}$ away from Norrköping. For Gösta, a new project after retirement was to visit all nature reserves in the county. His wife was still working, but he had an acquaintance who was going to join him. Some informants went on spontaneous trips to places outside the city or just went for a car ride. Seven informants had summer cottages where they spent most of their time during summer. Birgitta said that she would readily move out there all year around, but she did not want to drive in the countryside during winter because of the darkness, which implies a capacity constraint that prevents her from living where she wants. When Jan retired, he and his wife moved out to the summer cottage, which is situated about $50 \mathrm{~km}$ from Norrköping city, while keeping an apartment in the city. They went into Norrköping more than they had planned to, to meet friends and grandchildren, to go to the cinema, for dentist appointments and so on. They coordinated their trips to the city very carefully. For example, when his wife was planning to meet her friends for lunch, she tried to make it on a day when they already had something else planned in the city. One informant was able to take the bus to the summer cottage, the others were dependent on having a car and being able to drive it. Those who did not drive or own a car were more or less dependent on other people for certain activities and errands, which imply mobility constraints. Inger explained that she did not want to drive anymore and had sold her car a few years ago. Since she lives in the city centre she readily walked for most activities, except to out-of-town shopping areas, and then her husband drove her.

Mobility constraints were described by Erik, who had a driving licence but could not afford a car, due to his low pension. Erik still worked during weekends, and on those occasions he borrowed a car from his employer, while other days he cycled within the city.

With the car I'm more spontaneous. Then I can go out here (out-of-town retail area) and have a coffee or go wherever I like, to shop and look at things. Last weekend I was at Jysk (an out-of-town store) and had a look, but otherwise I'm not able to go there. So I'm very dependent on the car, for my own sake. (Erik)

He would like to go out of the city on weekday evenings to watch matches and training, but it is not possible to get to those places by public transport and it is too far to cycle. Without a car it is a challenge to overcome distances, as much service and shopping has moved out of town. Even though the travel diaries show that he was quite mobile during the week, it becomes clear from the interview that he subjectively experiences his mobility as restricted. The social context has a bearing on how mobility constraints can be overcome and managed. Accordingly, some activities would not be performed without help from others. The social context also increases the demand for mobility, as in the above cases of people assuming new commitments for their families after leaving paid work.

The interviews reveal that travelling by car is not always desirable and that experiences of car transport are not solely positive. Some informants mention that they are trying to reduce their car use due to the high costs of fuel and of parking in the city. To plan their trips and to make several errands at the time is a money-saving strategy with many of the informants. Ulf, who uses the car almost every day, says that since he is not in such a hurry nowadays as he was when still working, he drives slower because he has noticed that it saves fuel. Christer plans his errands and thinks through the routes very carefully in order to save money and avoid going back and forth between places. According to his travel diary, however, he made several single errands by car during the diary week. Two of the informants mention the environment as a reason for cutting down on car use. Some informants explain that since they have plenty of time as pensioners, the need for quick transport by car has lost its importance, rather they have time to walk or bicycle for errands that used to be done by car. Bertil says that he now has time to fabricate errands: 
For example, if you used to take the car for shopping out of town, then you can think, "is it something small that I have to buy?", and then you can cycle there and get some exercise into the bargain. (Bertil)

The extended free time of retirees is thus a capacity resource for many that enables them to choose when, where and how to travel. The car is also described as inconvenient, due to parking problems and traffic congestion. Bertil says that when going to a sports game he prefers cycling, so as to avoid tailbacks to and from the arena, and according to the travel diary, he cycled to these events. Several informants find walking much more comfortable, they get exercise and fresh air and a chance to clear their minds. Eva remembers what it was like when she was still working (as a teacher) and had to travel by car most days.

Actually it was mostly because of the time, it takes $5 \mathrm{~min}$ by car and $25 \mathrm{~min}$ on foot /... . . . and you are often in a hurry and have to be there ten to eight or something. I walked and cycled sometimes, but I have used the car a lot /.../ Then I've also been thinking "how nice it would be to walk back home"... because that is the best way I think to clear one's thoughts and look around and to think and wonder, and process what has happened and reflect about tomorrow. As a teacher you are always making plans, and you could do that while walking, you don't have the time when you drive because then you have to concentrate on what's happening around you. It is not at all the same relaxation, or unwinding, because when you walk you have the time to do that, and also when you cycle. (Eva)

Her example illustrates how the coupling constraint in having to be at a certain place at a certain time limits the individual's freedom to choose transport mode and in Eva's case, being committed to the car made it difficult to fully recover from work. Eva now appreciates having time to walk to most of her activities.

\section{Discussion}

The aim of this article was to explore to what extent car transport is used and valued for everyday mobility upon retirement. In contrast to previous research on older people's mobility that has studied larger populations and slightly older people [10-13], the present study has focused on a specific group that are relatively healthy, well-off, and have the possibility to choose between different modes of transport. To the best of our knowledge, this is the first qualitative study that explores how retirement as a key event in later life can influence travel behaviour. The time-geographical approach and its conceptual tools were helpful in order to understand choices of transport modes and opportunities as well as mobility constraints. In some cases, to travel lies beyond the individual's own needs and decisions and are determined by other people's needs (e.g., children and old parents), by the support provided by other people, and by the locations of activities and services (e.g., retail areas, golf courses and summer cottages). In some cases, individuals are free to travel when, where and how they want.

Much research has explored mobility among older people. With our approach, using a qualitative method to study a small sample in a specific context of a middle-sized city in Sweden we have been able to provide a better understanding of the contextual surroundings that create demands for car use. Four different time-geographical contexts have been explored: the project, activity, social, and geographical context. The interviews reveal that the informants have many projects that they would not be able to perform if they did not have access to a car: shopping, household projects and recreational activities such as playing golf. Many projects can, however, be implemented by other means of transport, but the car offers more choices of locations where these projects will be implemented. The importance of the car does not seem to have changed upon retirement, albeit it is partly used for other reasons than before. A substantial part of the extended free time many now have as pensioners is used so that others can save time. It is clear that the informant's social context implies new coupling constraints. Commitments to family members, engagement in associations and spouses' occupations affect how much and when they use the car, and also affect their overall daily mobility. The car saves time, both for themselves but also for other people who need help or want a ride. The car is thus a resource for those who do not own it or drive it. This is exemplified by Lars in this study, who uses the car mostly for chauffeuring his family and making up for time that he lost with them when he was working too much. Similar results were obtained by Zeitler and Buys [40] in a study of older people in suburban environments in Brisbane, Australia. Some informants would not be able to carry out certain activities and projects without the support of friends and relatives who have a car. Erik in this study, who does not have access to a car in the household, expresses that he occasionally experiences spatial constraints as regards getting out of town. However, owing to his social networks, he is still able to manage those trips.

By using a combination of travel diaries and qualitative interviews, we have been able to explore how the informants reason regarding their travel behaviour but also how they actually travel. Our empirical analysis complements the existing literature about the meaning of the car in general and for the newly retired in particular [cf. 32, 41]. For example, although the car implies freedom and independence in many cases, it is also experienced as inconvenient. Many of the informants said 
that they were taking the opportunity to walk instead of driving, not only because they had the time but also for health reasons, for saving fuel, parking money and for the pleasures that they experienced by walking. Their mobility has thus changed in that they after retirement have extended free time, which gives the ability to choose mode of transport. In many cases, this results in increased walking or cycling. According to the travel diaries however, the car was the most used transport mode during the diary week, and it was often used for short trips, and for making one single errand. Car use seems to be a rather unreflective habitual behaviour and is not fundamentally reconsidered in this new phase in life. In Lars's case for example, he drove his wife to work, and the option of walking or cycling with her did not seem to have occurred to him. Intentions to change travel mode is determined by attitudes, norms and perceived control [42]. However, habits have a strong effect on the actual behaviour, as long as the circumstances are relatively stable [42, 43]. Since all of the informants retired "in place", the activity destinations, such as shopping areas and social networks, remain the same. Even though their attitudes towards walking and cycling are positive, habits developed earlier in life are important for understanding their post-retirement travel behaviour. Further, the answers given during the interviews might reflect a perceived social norm, e.g., their responses are influenced by what they believe is right, based for example on discourses on sustainable travel and active ageing.

Two lines of portrayal concerning older people as car users have been particularly evident in transport research literature in recent years. One line of research suggests that older people are car dependent and that frequent car use among a growing ageing population will lead to increased environmental problems if their assiduous use of the car is to continue, and that car dependency will lead to mobility decline once people have to give up driving $[4,27,36,37]$. The other line of research points out that older people are especially liable to become isolated, dependent and immobile if they have to give up driving and rely on other people or on public transport [30, 33]. With this line of thought, older people should be encouraged to prolong their driving [44]. The findings from this study do not support either of these two lines of portrayal.

To cease driving is a non-issue for those who still drive, it is too early for them to even think of the day when they will no longer be fit to drive. We might ask what the informants' mobility will be like when they give up driving. Driving cessation is mostly a gradual process whereby drivers reduce their driving before giving it up completely [45]. Thoughts of giving up driving have been expressed as very emotional, many older people being worried by the prospect of becoming dependent on others and losing their ability of getting out and about [27]. Several studies show that driving cessation leads to decreased mobility and reduces the possibility of engaging in voluntary and social activities [46, 47]. However, it has also been shown that the consequences of driving cessation have not been as negative for the individual as they had anticipated and that many express a fairly high degree of mobility after ceasing to drive $[46,48]$. These results stem from studies among urban older people with close access to shops and services. It can be expected that older people in urban areas without such services, and where public transport is less available, will experience more negative effects of driving cessation $[49,50]$. Further, differences in mobility satisfaction after ceasing to drive depend for example on knowledge about alternative transport options, and the meaning of the car prior to giving up driving [51].

The ability to perform activities is dependent on various resources [6]. It can be assumed that when the informants quit driving their mobility will depend on the resources available to them such as the possibility of getting rides from spouses or friends, walking distance to important amenities and so on. For some, mobility constraints will probably be experienced due to a lack of resources.

\section{Conclusions}

Our results show that retirement affects travel mode choices in different ways. In managing everyday life projects, the car was important, for the driver as well as for family members and friends who needed help or a car ride. The car symbolises independence and freedom for newly retired people and so their attitudes to the car was no different from people at earlier stages in life. An important contribution of this study is that newly retired people are not as active as could be expected but that the car remains important in order to meet new time-space constraints upon retirement. As we have studied people living in a middle-sized city, most of what people need in everyday life can be found within a relatively small area. The informants could walk or cycle in order to carry out many out-of-home activities. In general, they were not as enthusiastic about using the car as could be expected from such a motorised generation. Although the car was used more than other transport modes, being able to walk and cycle now that they had more time as retirees was highly valued. Based on the informants' positive attitudes towards walking and cycling, we want to point out (though this was not the study's primary purpose) that our results indicate that urban residents that are retiring now and in the future are a key target group in transport planning when it comes to reduce car use in favour of slow modes of transport. The kind of results presented in this and similar studies can contribute with valuable knowledge for transport planning and be essential for whether planning will manage to meet the growing ageing population's mobility needs in the future and at the same time reduce car density in urban areas. Further research is needed to better understand the mobility needs of those in different geographical contexts, what various 
situations they meet and how they get along with time-space constraints in everyday life; in order to provide transport planners with knowledge of how to increase the use of sustainable transport modes while promoting mobility in an aging population.

Acknowledgments This study is part of an ERA-NET project entitled "Senior Life Transition Points and their Implications for Everyday Mobility", which is funded by Vinnova - Swedish Governmental Agency for Innovation Systems. The authors would like to thank Vinnova for financial support and Sonja Forward at VTI, for helpful comments on an earlier version of the paper.

Open Access This article is distributed under the terms of the Creative Commons Attribution 4.0 International License (http:// creativecommons.org/licenses/by/4.0/), which permits unrestricted use, distribution, and reproduction in any medium, provided you give appropriate credit to the original author(s) and the source, provide a link to the Creative Commons license, and indicate if changes were made.

\section{References}

1. Siren A, Haustein S (2013) Baby boomers' mobility patterns and preferences: what are the implications for future transport? Transp Policy 29:136-144

2. Hjorthol RJ, Levin L, Siren A (2010) Mobility in different generations of older persons: the development of daily travel in different cohorts in Denmark, Norway and Sweden. J Transp Geogr 18:624633

3. Coughlin JF (2009) Longevity, lifestyle, and anticipating the new demands of aging on the transportation system. Public Works Manag Policy 13:301-311

4. Rosenbloom S (2001) Sustainability and automobility among the elderly: an international assessment. Transportation 28:375-408

5. Beige S, Axhausen KW (2012) Interdependencies between turning points in life and long-term mobility decisions. Transportation 39: $857-872$

6. Ellegård K (1999) A time-geographical approach to the study of everyday life of individuals - a challenge of complexity. GeoJournal 48:167-175

7. Scheiner J (2014) Gendered key events in the life course: effects on changes in travel mode choice over time. J Transp Geogr 37:47-60

8. Verhoeven M (2010) Modelling life trajectories and transport mode choice using Bayesian belief networks. Dissertation, Technische Universiteit Eindhoven

9. Berg J, Levin L, Abramsson M, Hagberg JE (2014) Mobility in the transition to retirement - the intertwining of transportation and everyday projects. J Transp Geogr 38:48-54

10. Mollenkopf H, Baas S, Marcellini F, Oswald F, Ruoppila I, Széman $\mathrm{Z}$ et al (2005) Mobility and the quality of life. In: Mollenkopf $\mathrm{H}$, Marcellini F, Ruoppila I, Széman Z, Tacken M (eds) Enhancing mobility in later life: personal coping, environmental resources and technical support; the out-of-home mobility of older adults in urban and rural regions of five European countries. Ios Press, Amsterdam, pp 279-288

11. Hildebrand ED (2003) Dimensions in elderly travel behaviour: a simplified activity-based model using lifestyle clusters. Transportation 30:285-306

12. Ziegler F, Schwanen T (2011) 'I like to go out to be energised by different people': an exploratory analysis of mobility and wellbeing in later life. Ageing Soc 31:758-781
13. Haustein S (2012) Mobility behavior of the elderly: an attitudebased segmentation approach for a heterogeneous target group. Transportation 39:1079-1103

14. Hägerstrand T (1970) What about people in regional science? Reg Sci Assoc Pap 24:7-21

15. Giddens A (1984) The constitution of society: outline of the theory of structuration. Polity Press, Cambridge

16. Hägerstrand T (1991) Tidsgeografi [Eng: Time-geography]. In: Carlestam G, Sollbe B (eds) Om tidens vidd och tingens ordning: texter av Torsten Hägerstrand. Statens råd för byggnadsforskning, Stockholm

17. Blomkvist P, Kaijser A (1998) Introduktion: De osynliga systemen [Eng: Introduction: the invisible systems]. In: Blomkvist P, Kaijser A (eds) Den konstruerade världen: Tekniska system i historiskt perspektiv. Brutus Östlings bokförlag symposium, Stockholm, pp 7-19

18. Nordell K (2002) Kvinnors hälsa — en fråga om medvetenhet, möjligheter och makt. [Eng. Women's health-about awareness, possibilities and power]. Dissertation, University of Gothenburg

19. Lanzendorf M (2003) Mobility biographies. A new perspective for understanding travel behaviour. Paper presented at the 10th International Conference on Travel Behaviour Research: Moving through nets: The physical and social dimensions of travel. Lucerne, 10-15. August 2003

20. Prillwitz J, Harms S, Lanzendorf M (2006) Impact of life-course events on car ownership. Transp Res Rec 1985:71-77

21. Prillwitz J, Harms S, Lanzendorf M (2007) Interactions between residential relocations, life course events, and daily commute distances. Transp Res Rec 2021:64-69

22. Mollenkopf H, Marcellini F, Ruoppila I, Széman Z, Tacken M, Wahl H-W (2004) Social and behavioural science perspectives on out-of-home mobility in later life: findings from the European project MOBILATE. Eur J Ageing 1:45-53

23. Transport Analysis (2014) The Swedish national travel survey 2012-2013. Available at http://www.trafa.se/en/Statistics/Travelsurvey-RVU/. Accessed 23 Oct 2014, 11:22

24. Gilleard C, Higgs P (2000) Cultures of ageing: self, citizen and the body. Prentice Hall, Harlow

25. Lindgren E (2010). Samhällsförändring på väg. Perspektiv på den svenska bilismens utveckling mellan 1950 och 2007. [Eng: Social change on the way. Perspectives on the Swedish automobility development between 1950 and 2007]. Dissertation, Umeå University

26. Miranda-Moreno LF, Lee-Gosselin M (2008) A week in the life of baby boomers: how do they see the spatial-temporal organization of their activities and travel? Transportation 35:629-653

27. Buys L, Snow S, van Megen K et al (2012) Transportation behaviours of older adults: an investigation into car dependency in urban Australia. Australas J Ageing 31:181-186

28. Hagman O (2003) Mobilizing meanings of mobility: car users' constructions of the goods and bads of car use. Transp Res D Transp Environ 8:1-9

29. Polk M (1998) Gendered mobility: a study of women's and men's relations to automobility in Sweden. Dissertation, University of Gothenburg

30. Siren A, Hakamies-Blomqvist L (2005) Sense and sensibility. A narrative study of older women's car driving. Transp Res F 8: 213-228

31. Musselwhite C, Haddad H (2010) Mobility, accessibility and quality of later life. Qual Ageing Older Adults 11:25-37

32. Davey JA (2007) Older people and transport: coping without a car. Ageing Soc 27:49-65

33. Alsnih R, Hensher DA (2003) The mobility and accessibility expectations of seniors in an aging population. Transp Res A Policy Pract 37:903-916

34. WHO (2012) Strategy and action plan for healthy ageing in Europe 2012-2020. WHO, Copenhagen 
35. Siren A, Hakamies-Blomqvist L (2004) Private car as the grand equaliser? Demographic factors and mobility in Finnish men and women aged 65+. Transp Res F 7:107-118

36. Liddle J, Gustafsson L, Bartlett H et al (2012) Time use, role participation and life satisfaction of older people: impact of driving status. Aust Occup Ther J 59:384-392

37. Pillemer K, Wells NM, Wagenet LP et al (2011) Environmental sustainability in an aging society: a research agenda. J Aging Health 23:433-453

38. Vrotsou K (2010) Everyday mining: exploring sequences in eventbased data. Dissertation, Linkoping University

39. Hsieh HF, Shannon SE (2005) Three approaches to qualitative content analysis. Qual Health Res 15:1277-1288

40. Zeitler E, Buys L (2015) Mobility and out-of-home activities of older people living in suburban environments: 'because I'm a driver, I don't have a problem'. Ageing Soc 35:785-808

41. Kostyniuk LP, Shope JT (2003) Driving and alternatives: older drivers in Michigan. J Saf Res 34:407-414

42. Bamberg S, Ajzen I, Schmidt P (2003) Choice of travel mode in the theory of planned behavior: the roles of past behavior, habit, and reasoned action. Basic Appl Soc Psychol 25:175-187

43. Carrus G, Passafaro P, Bonnes M (2008) Emotions, habits and rational choices in ecological behaviours: the case of recycling and use of public transportation. J Environ Psychol 28:51-62
44. Siren A, Meng A (2013) Older drivers's self-assessed driving skills, driving-related stress and self-regulation in traffic. Transp Res F Traffic Psychol Behav 17:88-97

45. Siren A, Haustein S (2014) What are the impacts of giving up the driving licence? Ageing Soc, FirstView:1-18

46. Oxley J, Chariton J, Scully J et al (2010) Older female drivers: an emerging transport safety and mobility issue in Australia. Accid Anal Prev 42:515-522

47. Curl AL, Stowe JD, Cooney TM, Proulx CM (2014) Giving up the keys: how driving cessation affects engagement in later life. The Gerontologist 54:423-433

48. Berg J, Levin L (2011) Äldres vardagliga resor: val av färdmedel och erfarenheter av kollektivtrafik. [Eng: Older people's everyday travel: choice of travel mode and experience of public transport] VTI rapport 734. VTI, Linkoping

49. Shergold I, Parkhurst G, Musselwhite C (2012) Rural car dependence: an emerging barrier to community activity for older people. Transp Plan Technol 35:69-85

50. Marottoli RA, de Leon CFM, Glass TA, Williams CS, Cooney LM, Berkman LF (2000) Consequences of driving cessation: decreased out-of-home activity levels. J Gerontol B Psychol Sci Soc Sci 55: 334-340

51. Musselwhite CBA, Shergold I (2013) Examining the process of driving cessation in later life. Eur J Ageing 10:89-100 